\title{
Crescimento Econômico e Lei de Thirlwall: Uma Análise para Economias Latino-Americanas
}

\section{Economic Growth and Thirlwall's Law: An Analysis for Latin American Economies}

\author{
Luis Eduardo Esteves* \\ Fernando Motta Correia**
}

Resumo: O objetivo do presente estudo é demonstrar se, utilizando a metodologia Engle-Granger, os cinco países latino-americanos selecionados (Argentina, Brasil, Chile, Colômbia e México) realmente observaram para o período 19802005, uma variação na sua elasticidade renda das importações, de forma a que esta tenda a suavizar a restrição imposta pela lei de Thirlwall ao crescimento destes países, i.e., espera-se que um fluxo de capitais negativo, ou seja, uma fuga de capitais reduza a elasticidade renda das importações, implicando em uma maior taxa de crescimento que a possível se esta se mantiver constante durante esta fuga. Os resultados mostram que a lei de Thirlwall parece ser uma boa representação para a trajetória de crescimento destes, sendo esta determinada fundamentalmente, pelas exportações e pela elasticidade renda das importações.

Palavras-chave: Crescimento. América Latina. Macroeconomia aberta.

Abstract: The objective is to demonstrate, using the Engle-Granger methodology, the five selected Latin American countries (Argentina, Brazil, Chile, Colombia and Mexico) actually observed for the period 1980-2005, a variation in its income elasticity of imports so that it tends to soften the constraint imposed by the law of Thirlwall growth of these countries, ie, it is expected that a negative flow of capital, or a flight of capital, reduce the income elasticity of imports, implying a higher growth rate than is possible if it is kept constant during this flight. The results show that Thirlwall's Law seems to be a good representation for the trajectory of growth, which is determined primarily by exports and the income elasticity of imports.

\footnotetext{
* $\quad$ Especialista em Regulação da Agência Nacional do Petróleo. E-mail: lesteves@anp.gov.br

** Professor adjunto do Departamento de Economia da Universidade Federal do Paraná (UFPR). E-mail: fmcorreia@ufpr.br

Os autores agradecem os prestigiosos comentários do prof. Dr. Maurício Bittencourt que, definitivamente, contribuiu para melhorar a qualidade do artigo. Não obstante, os autores o isentam de quaisquer responsabilidades.
} 
Keywords: Growth. Latin America. Open economy macroeconomics.

JEL Classification: O40; O54; F43.

\section{Introdução}

No ano de 1979, Thirlwall, com seu trabalho The balance of payments constraint as an explanation of international growth rate differences, demonstra que os países crescem a diferentes taxas, pois estes encontram diferentes elasticidades renda das importações e elasticidades renda das exportações. Com este fato, tenta explicar por que o Reino Unido tem um menor crescimento que a média mundial.

Este novo campo da abordagem pós-keynesiana, inaugurado por Thirlwall, abre caminho para que a explicação das diferentes taxas de crescimento que é observada empiricamente obtenha outra explicação que não esteja correlacionada com a taxa de poupança de seus países ou mesmo com a distância que estejam de seu estado estacionário.

No caso dos países latino-americanos há uma forte identificação com a lei de Thirlwall, de modo que diversas pesquisas empíricas são realizadas para demonstrar que o crescimento destes países de fato, é restringido por esta relação de longo prazo.

O objetivo do presente estudo é demonstrar se, utilizando a metodologia Engle-Granger, os cinco países latino-americanos selecionados (Argentina, Brasil, Chile, Colômbia e México) realmente observaram para o período 1980-2005, uma variação na sua elasticidade renda das importações, de forma a que esta tenda a suavizar a restrição imposta pela lei de Thirlwall ao crescimento destes países, i.e., espera-se que um fluxo de capitais negativo, ou seja, uma fuga de capitais reduza a elasticidade renda das importações, implicando em uma maior taxa de crescimento que a possível se esta se mantiver constante durante esta fuga.

Espera-se, ainda, que a importância da conta capital para o país na obtenção de divisas externas também seja um determinante da sensibilidade da elasticidade renda das importações. Assim, quanto menor for a razão entre o valor real das exportações e o valor real dos fluxos de capital, maior será a sensibilidade da elasticidade renda das importações com relação ao fluxo de capitais do país.

O artigo está dividido em seis seções: a segunda seção faz uma breve discussão sobre as principais teorias do crescimento econômico e em que contexto a lei de Thirlwall está inserida, dando atenção a uma breve revisão acerca de trabalhos que se utilizam dessa discussão; a terceira seção demonstra o quão importante é a elasticidade renda da demanda por importações para os modelos que seguem a abordagem keynesiana trabalhando com economias abertas, e como ela é fundamental para a determinação de um crescimento com restrição ao balanço de pagamentos; a quarta seção contém a apresentação dos dados, e a evolução do 
modelo econômico, para o modelo econométrico; já a quinta seção contém uma explicação da metodologia a ser utilizada e os resultados obtidos pelo modelo; por fim, a sexta seção contém as considerações finais do trabalho.

\section{Crescimento Econômico e Lei de Thirlwall: Algumas Considerações}

Os primeiros estudos sobre os fatores determinantes do crescimento econômico remontam aos fundadores da ciência econômica, Adam Smith e David Ricardo. Frequentemente é postulado a Smith um modelo de crescimento econômico onde a especialização no mercado de trabalho criaria retornos crescentes, de modo a gerar um modelo de crescimento perpétuo, sendo o determinante fundamental do crescimento econômico o tamanho do mercado, onde, quanto maior o mercado, maiores os incentivos à especialização dos trabalhadores. Já a Ricardo, é dada a visão do estagnacionismo e o sentimento de uma ciência econômica lúgubre (dismal science), já que suas ideias incorporadas pela lei dos retornos marginais decrescentes criariam um modelo no qual o acúmulo dos fatores produtivos geraria, desde que um fator fosse constante, neste caso a terra, um estado estacionário inexorável (ADELMAN, 1972).

Após os estudos iniciais sobre os determinantes do crescimento econômico, este ramo de estudos da ciência econômica fica esquecido, muitas vezes jogado a notas de rodapé (PASINETTI, 1979). Harrod (1939) e Domar (1946) desenvolvem uma discussão sobre os determinantes do crescimento econômico, retomando as análises sobre o tema; o mais interessante é que foi necessário um resultado que demonstrasse que o crescimento estava fadado a ser instável, sendo estável somente por uma "feliz coincidência" entre três taxas de crescimento determinadas exogenamente ao modelo ${ }^{1}$, que impulsionaria novos estudos sobre o crescimento.

É na tentativa de solucionar o modelo e obter um crescimento que não seja determinado somente por uma "feliz coincidência" entre diferentes taxas de crescimento que em 1957, Solow escreve o seu paper, Contribution to the Theory of Economic Growth. Observa-se neste artigo que, ao inserir-se uma função de produção tipicamente associada com a abordagem neoclássica, que, consequentemente, flexibiliza o coeficiente técnico do capital de tal forma a que este possa ser associado a qualquer quantidade de trabalho, dependendo somente dos preços relativos do sistema, emerge um resultado que retoma o pensamento ricardiano de que o crescimento econômico estaria fadado a ter um estado estacionário. Este resultado é derivado da lei dos retornos decrescentes, que incidiria sobre os fatores produtivos, gerando uma produtividade marginal decrescente. Neste sentido, conforme a economia acumula capital, também reduz a produtividade deste, a ponto de inviabilizar o crescimento econômico.

1 As três taxas correspondem à taxa de crescimento populacional, à taxa de crescimento garantida, e à taxa de crescimento necessária (JONES, 1979). 
O modelo derivado por Solow (1957) acaba por enraizar a ideia já predominante na época, inserida pela função de produção Cobb-Douglas, que então remunerava cada fator produtivo conforme a sua contribuição marginal. Esta abordagem fechava o modelo de crescimento econômico segundo a abordagem neoclássica, demonstrando que as economias estavam fadadas a terem um estado estacionário, e inclusive, que a renda seria distribuída a cada fator de produção da maneira mais eficiente possível: segundo a produtividade marginal de cada fator produtivo.

Com o objetivo explícito de obter uma teoria alternativa para a distribuição de renda, Kaldor (1956), inspirado em uma passagem econômica de Keynes publicada inicialmente em Treatise on Money, a widow's cruse, acaba por dividir a economia em duas classes de renda, uma que deriva a sua renda do capital, e a outra que deriva a sua renda dos salários. É neste artigo que vemos pela primeira vez, emergir como um resultado, a equação de Cambridge, que demonstra a velha e enraizada ideia de uma distribuição da renda determinada pela acumulação de capital, neste caso, determinada pela propensão média e marginal a poupar dos capitalistas.

Tanto a abordagem pós-keynesiana, quanto a abordagem neoclássica selaram a sua separação justamente na determinação destes dois modelos, que resultariam em diversos outros trabalhos, mas todos com uma característica comum, a tentativa de desvendar os determinantes do crescimento econômico.

$\mathrm{Na}$ abordagem neoclássica, observa-se que os modelos evoluíram no sentido de determinar o crescimento via transbordamentos provenientes de externalidades não capturadas pelo progresso técnico e pelo investimento em capital humano, de forma a que não haja mais um estado estacionário que relacione o produto per capita, proporcionando um contínuo crescimento da economia, resultado condizente com a evidência empírica. Contudo, nestes novos modelos, ainda existe um estado estacionário, determinado em termos de produto por unidades de eficiência, ou seja, um produto que leve em consideração o progresso técnico. (ROMER, 1986; LUCAS, 1988)

Já a abordagem keynesiana continuou na tentativa de solidificar a equação de Cambridge, obtendo resultados cada vez mais robustos, inclusive determinados com a introdução de funções utilidades e de agentes racionais e otimizadores, mas ainda divididos em duas classes, não mais de renda ${ }^{2}$, mas sim classes sociais: os capitalistas (que obtém toda a sua renda do capital); e, trabalhadores (que obtém a sua renda do capital e do trabalho) (BARANZINI, 1991).

Diversos estudos seguiram, tanto segundo a abordagem neoclássica, quanto na abordagem pós-keynesiana, mas nenhum ainda obtinha o grau de realismo vivido

2 A determinação de duas classes sociais, ao invés de duas classes de renda, provém da "correção" que Pasinetti (1964) faz em relação à Kaldor (1956), à qual Pasinetti (1964) chama de logical slip, já que era dada a possibilidade de o trabalhador poupar, mas este nada recebia de sua poupança. Pasinetti (1964), em si, introduz não uma "correção", propriamente falando, e sim a noção de duas classes sociais, não mais duas classes de renda, como derivado, mas não suposto, inicialmente no modelo de Kaldor (1956). Com a suposição de duas classes sociais, ao invés de duas classes de renda, Pasinetti (1964) acaba por obter a equação de Cambridge sem a necessidade de uma suposição. 
pelas economias em desenvolvimento, e muito menos as economias latino-americanas, que observavam em sua história, um crescimento econômico sempre restringido por estrangulamentos de setores, sendo o principal deles o externo. (TAVARES, 1972)

O pensamente Cepalino, sempre focado nos problemas das economias latino-americanas, observa que o principal determinante do crescimento dos países latino americanos reside nos termos de troca. Portanto, quando estes favoreciam aos países, ou seja, quando havia uma elevação no preço dos produtos primários em relação aos preços dos bens manufaturados, os países viviam um período de crescimento. Contudo, no momento em que os termos de troca se deterioravam, estes sofriam com sérias restrições externas influenciadas pelo balanço de pagamentos, que estrangulava o crescimento destes países.

O desenvolvimento do pensamente cepalino, permanece, inicialmente em torno de um desenvolvimento com dependência, principalmente em relação à demanda externa, ainda um fator determinante para o crescimento dos países da região, já que seus produtos obtinham a sua realização como mercadoria somente nos mercados centrais. Prebisch (1950) desenvolve o modelo centro-periferia, com o objetivo de demonstrar que os países centrais determinavam o seu crescimento, mas que os países periféricos, estavam fadados a terem um crescimento que dependia da demanda dos países centrais.

No ano de 1979, Thirlwall, com seu trabalho The balance of payments constraint as an explanation of international growth rate differences, demonstra que os países crescem a diferentes taxas, pois estes encontram diferentes elasticidades renda das importações e elasticidades renda das exportações. Com este fato, tenta explicar por que o Reino Unido tem um menor crescimento que a média mundial.

Este novo campo da abordagem pós-keynesiana, inaugurado por Thirlwall, abre caminho para que a explicação nas diferentes taxas de crescimento que é observada empiricamente obtenham outra explicação que não esteja correlacionada com a taxa de poupança de seus países ou mesmo com a distância que estejam de seu estado estacionário.

Neste estudo surge a fundamentação de uma relação já observada pelo pensamento cepalino de uma restrição ao crescimento dos países devido ao balanço de pagamentos (BERTOLA et al., 2002). É justamente com o desenvolvimento do modelo apresentado por Thirlwall, que os países latino-americanos, tanto se identificam e observam tal como uma lei, a ponto desta relação tornar-se conhecida como Lei de Thirlwall, que em sua determinação mais básica, demonstra ser o crescimento do país restrito pela razão entre a taxa de crescimento das exportações e a elasticidade renda das importações.

A identificação dos países latino-americanos com a Lei de Thirlwall é tamanha que diversas pesquisas empíricas são realizadas para demonstrar que o crescimento destes países de fato, é restringido por esta relação de longo prazo (MCCOMBIE, 1992). 
Thirlwall e Hussain (1982), atentos à exploração da teoria de crescimento com restrição ao balanço de pagamentos e observando a realidade vivida pelos países em desenvolvimento, onde os fluxos de capitais também são de extrema importância para o crescimento, acrescentam o fluxo de capitais no modelo de Thirlwall (1979), com o objetivo de tornarem-no mais próximo da realidade observada pelos países em desenvolvimento.

Mesmo com esta introdução, deve-se ressaltar que, mesmo no longo prazo, os fatores determinantes do crescimento restrito pelo balanço de pagamentos ainda dependem da taxa de crescimento das exportações e da elasticidade renda da demanda por importações. Mesmo tendo um fluxo de capitais, de forma a viabilizar um maior crescimento no curto prazo, ou seja, uma estratégia de debt-led growth, esta dívida acumulada no decorrer do crescimento maior que o determinado pela lei de Thirlwall, implica em uma restrição maior ao crescimento futuro, isto, pois em algum momento a dívida deve ser paga pelo país. (MCCOMBIE; THIRLWALL, 1994).

Uma evidência da lei de Thirlwall para o Brasil é obtida pelo estudo de Bértola et al. (2002). Utilizando-se do método de co-integração, os autores observam que para o Brasil, durante o período de 1890-1973, a lei de Thirlwall realmente acaba por restringir o crescimento. É interessante ressaltar que os autores preocupam-se com o período de seus dados, justificando o término do período no ano de 1973 devido ao "[...] 1970s were years of high capital inflows and debt-led growth" (BÉRTOLA et al., p. 137, 2002).

Outra evidência da lei de Thirlwall é obtida para os países da América Central, novamente utilizando o método de co-integração, Moreno-Brid e Pérez (1999), introduzem no modelo os termos de troca, ou seja, os autores não supõem que haja uma paridade do poder de compra nestes países. Neste sentido, os autores selecionam uma gama de economias e observam a evolução temporal nos termos de troca. Como resultando, os autores encontram uma relação de longo prazo entre a taxa de crescimento das exportações, os termos de troca e o crescimento dos países.

Mesmo com variações sobre as elasticidades a lei de Thirlwall ainda é válida, mas agora sem o contexto de uma elasticidade renda das importações constante, ou seja, ao introduzir o fluxo de capitais na determinação da lei de Thirlwall, como o fizeram Thirlwall e Hussain (1982), a elasticidade renda das importações pode tornase endógena para compensar os fluxos de capitais e manter a lei de Thirlwall válida.

Barbosa-Filho (2004) chama a atenção que a elasticidade renda das importações para o Brasil é variável, de modo que uma elevação da entrada do fluxo de capitais acaba por elevar a elasticidade renda das importações, de forma a reduzir a possibilidade de crescimento determinada pela maior quantidade de capitais disponíveis ao país. Enquanto uma fuga de capitais é seguida por uma redução da 
elasticidade renda das importações, de modo a suavizar a restrição ao crescimento que o país sofreria.

\section{A Importância da Elasticidade Renda da Demanda por Importações}

Podemos observar pelo modelo de Thirlwall (1979) e pelo modelo de Thirlwall e Hussain (1982), que a elasticidade renda das importações é de extrema importância, já que quanto maior seja esta, menor será a possibilidade de crescimento que o país efetivamente incorrerá. Assim, é de se esperar que países com altas taxas de crescimento tenham baixas elasticidades renda das importações, ou se não o tiverem, tenham altas elasticidades da demanda por exportações, o que garantiria, mesmo com altas elasticidades renda das importações, uma elevada tendência de crescimento econômico, segundo a lei de Thirlwall.

Seguiremos o desenvolvimento realizado por McCombie e Thirlwall (1994), compreendendo o modelo estendido para a entrada de capitais, feito por Thirlwall e Hussain (1982). Iniciamos pela restrição do balanço de pagamentos, que é dada pela equação (1):

$$
P X+F=P^{*} E M
$$

A equação (1) declara que a renda obtida com as exportações mais o fluxo de capitais que entraram no país, devem ser iguais às importações realizadas por este país.

Procedemos supondo a função demanda por exportações na forma:

$$
X=a\left(\frac{P}{P^{*} E}\right)^{\beta} Z^{\alpha}
$$

Pela equação (2), observamos que a demanda por exportações, $X$, é relacionada com os meios de troca, e com a renda do resto do mundo, Z. Esta também tem elasticidades renda da demanda, representada por $\alpha$, e a elasticidade preço das importações, $\beta$.

A função demanda por importações é suposta como sendo:

$$
M=b\left(\frac{P^{*} E}{P}\right)^{\eta} Y^{\pi}
$$

A equação (3) demonstra que a demanda por importações depende dos termos de troca, e da renda interna deste país, Y. Também depende dos parâmetros $\eta$, aqui a elasticidade preço das importações e de $\pi$, a elasticidade renda das importações.

O modelo de Thirlwall e Hussain (1982) é obtido por estas três equações, quando, então, obtém-se a taxa de crescimento das equações (1), (2) e (3), e inse- 
rem-se as taxas de crescimentos obtidas em (2) e (3), na taxa de crescimento obtida em (1), resultando em:

$$
y_{b}=\frac{(\varsigma \beta+\eta+1)(p-p *-e)+\theta \alpha z+(1-\theta)(f-p)}{\pi}
$$

Sendo que o parâmetro $\theta$ representa a participação das exportações no conjunto de fluxos de moedas estrangeiras para o país, i.e., na soma entre as exportações e no fluxo de capitais. Assim, a equação (4) afirma que a taxa de crescimento de um determinado país é restringida pelo balanço de pagamentos.

Uma breve comprovação de evidência empírica da lei de Thirlwall, tanto com a introdução do fluxo de capitais, quanto sem a inclusão deste, para vários países pode ser obtida em: Thirlwall e Hussain (1982), Bértola, Higachi e Porcile (2002), Thirlwall e McCombie (1994).

Por fim, observe que a elasticidade renda da demanda por importações é de fundamental importância no modelo. Isto ocorre porque uma elevada elasticidade renda da importação acaba por reduzir o crescimento, mas com a introdução dos fluxos de capitais ocorre uma tendência decrescente na taxa de crescimento resultante, p.ex., uma elevação exógena da elasticidade renda das importações pode ser contornada com um maior fluxo contínuo, i.e., uma maior taxa de crescimento do fluxo de capitais para o país. Esta estratégia de crescimento é conhecida como debt-led growth.

Desde que a elasticidade seja de fundamental importância para a lei de Thirlwall, e esta tem se mostrado robusta aos testes empíricos realizados, a contribuição do trabalho segue na demonstração de como as elasticidades renda da demanda por importações podem variar conforme ocorrem entradas ou saídas de fluxos de capitais dos países, i.e., como os fluxos de capitais se relacionam com as elasticidades renda da demanda para um conjunto selecionado de países da América Latina.

\section{Os Dados e o Modelo Econométrico}

Os dados referentes às importações, exportações, produto, índice de preços dos países, fluxo da conta capital e deflatores, que foram obtidos junto ao site do FMI, no IFS - Internacional Financial Statistics. O deflator utilizado para a moeda estrangeira foi o índice de preços dos E.U.A., sendo que todos os deflatores têm como base o ano 2000.

O modelo econométrico utilizado pressupõe que os termos de troca não se alteraram no período, desconsiderando a sua influência sobre as importações, de forma a podermos aplicar o logaritmo na equação (3), e obtermos o seguinte resultado: 


$$
\log M=\log (b)+\pi \log Y
$$

Note que a equação (5) representa a relação que ocorre entre as importações e a renda, sendo o parâmetro $\pi$ a elasticidade renda das importações.

O objetivo da análise é determinar se a elasticidade renda das importações sofre influência da conta capital. Para tanto, obtemos os valores correntes da conta capital para cada país, e deflacionamos pelo índice de preços dos E.U.A., de forma a obter o fluxo real de entrada ou saída de capitais do país e observamos em que momento este fluxo tem o valor positivo ou negativo. Se este tiver valor negativo, isto significa que houve uma fuga de capitais daquele país com destino ao seu país de origem ou outra aplicação. Mas, se houver uma entrada de capitais líquida, a conta capital terá sinal positivo.

Desde que a conta capital seja extremamente volátil e oscile com frequência, contudo tenha um papel fundamental ao determinar expectativas, tanto em relação ao país quanto em relação ao crescimento deste, espera-se que haja uma multicolinearidade entre os fluxos de capital e o produto resultante. Entretanto, espera-se que o fluxo de capitais também represente as expectativas dos agentes de determinado país, de forma a que ao observar um fluxo de capitais negativo, os agentes determinem que neste período ocorra escassez de moeda estrangeira, o que influenciará, de alguma forma, a elasticidade renda das importações negativamente. Além disto, espera-se que quanto mais importante for a conta capital para o país obter moeda estrangeira, maior será o impacto de um fluxo negativo sobre a elasticidade renda das importações.

Uma forma de mensurar quão importante é a conta capital para o país seria a de obter um índice que seja representado pela razão entre as exportações e a conta capital, de forma a que quanto maior seja esta relação, menor será a importância da conta capital para o país obter recursos do exterior.

Se estes resultados forem determinados, pode-se afirmar que a elasticidade renda da demanda por importações é determinada endogenamente ao modelo de Thirlwall e Hussain (1982) que incorporam a conta capital como um fator determinante da restrição ao crescimento econômico, porque em períodos onde a conta capital encontra um valor negativo, a elasticidade renda da demanda é reduzida, uma vez que a expectativa dos agentes com relação aos fluxos de dólares em direção à economia suaviza as predições realizadas pela lei de Thirlwall, ocasionando um maior crescimento para o período do que aquele determinado anteriormente pela 'antiga' elasticidade renda das importações. Isto demonstraria que o fluxo de capitais acaba por modificar as expectativas dos agentes e, portanto, altera o resultado final estabelecido pela lei de Thirlwall, tornando o crescimento maior que o possível para o período em que haja uma restrição de capitais externos.

Para mensurar esta variação sobre a elasticidade renda das importações, criou-se uma variável dummy interativa com a renda, onde a variável dummy tem 
valor zero para os períodos onde a conta capital tem um valor positivo, e um valor de 1 quando a conta capital tem um valor negativo. Assim, espera-se que o modelo gere um coeficiente da variável dummy que seja negativo, e tanto maior quanto menor for a razão entre as exportações e a conta capital.

Portanto, o modelo econométrico a ser estimado é, na verdade:

$$
\log M=\log (b)+\pi \log Y+\beta \cdot D \cdot \log Y+u
$$

Onde, como vemos por (5.1), a variável dummy é interativa com a renda, portanto, tentando observar como a redução dos fluxos de capitais tende a reduzir ou aumentar a elasticidade renda da demanda, lembrando que a variável dummy tem valor um quando a conta capital tem um valor negativo.

\section{A Metodologia e os Resultados das Estimações}

A regressão será realizada pelo método de co-integração e seguirá a metodologia Engle-Granger. Esta metodologia é determinada por alguns passos que devem ser seguidos e são enumerados a seguir.

O primeiro passo consiste em observar se os dados das variáveis, em nível, sofrem do problema da não estacionariedade, de forma a que todas as variáveis tenham raízes unitárias, teremos variáveis que são integráveis de ordem 1 e, portanto, não estacionárias, ocasionando o problema de relação espúria entre as variáveis. Mas se apenas uma das variáveis observadas for não estacionária de ordem um, e a outra for estacionária de uma ordem distinta da observada na primeira variável, não poderemos utilizar a metodologia Engle-Granger.

Já no caso de as duas variáveis observadas neste trabalho serem estacionárias, então pode-se observar os resultados da regressão normalmente, sem a preocupação com uma relação espúria entre as variáveis, tomando os valores das estatísticas t e F para inferência estatística.

Desde que obtemos todas as variáveis não estacionárias, mas na mesma ordem de integração, pode-se realizar a regressão de forma a obter as elasticidades e os parâmetros estimados, obtendo, também, os resíduos desta estimação. Com os resíduos desta regressão, deve-se testá-los para observar se estes são integráveis de uma ordem inferior à obtida no teste da integração das variáveis em nível. Se tal fato ocorrer, têm-se que o método de regressão é plausível e que a regressão não é espúria, já que as duas variáveis têm um equilíbrio no longo prazo.

Iniciando-se o estudo observando se as variáveis, em nível, têm raízes unitárias, sendo a hipótese nula a de que estas não contêm tais raízes unitárias, utilizando-se para este fim o teste aumentado de Dickey-Fuller, ADF, e escolhendo a melhor defasagem, um modelo com tendência, isto é, inserindo uma variável para retirar a tendência temporal de séries que possam ser determinísticas, e o intercepto, pelo critério de Schwarz. Os resultados estão sumarizados na Tabela 1. 


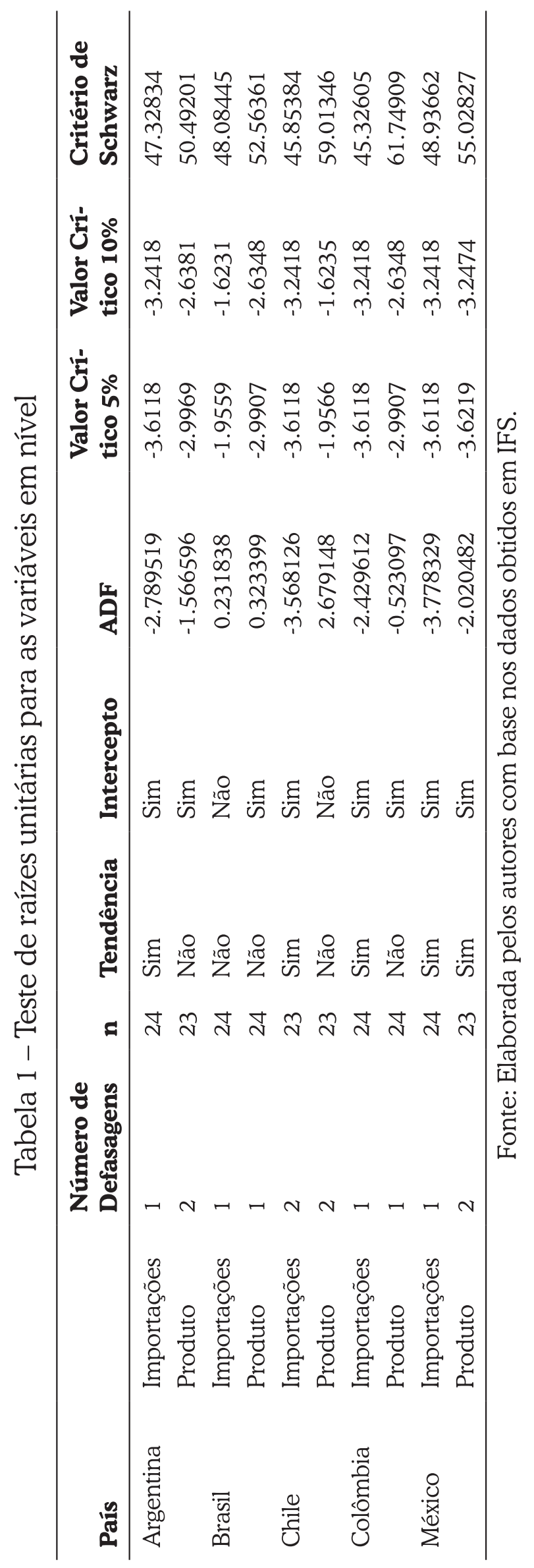

ESTEVES, L. E.; CORREIA, F. M. Crescimento econômico e Lei de Thirlwall: uma análise... 
Desde que a hipótese nula seja a hipótese de que não haja raiz unitária nessas relações, observamos que para os dados de importações e do produto destes países, somente para o Chile, aceita-se a hipótese nula de que não haja raiz unitária para as importações à $5 \%$, enquanto para o produto, aceita-se a hipótese nula de que não haja raiz unitária ao nível de significância de 10\%. Para todos os demais países tem-se que a hipótese nula é rejeitada ao nível de significância de 10\%, com base no teste $\mathrm{ADF}$, tanto para as séries de importações quanto para as séries dos produtos. Consequentemente tem-se que os países, excluindo-se o Chile, podem sofrer com o problema de relação espúria, determinadas pela mesma tendência entre as séries.

O passo seguinte a esta análise inicial dos dados, seguindo a metodologia Engle-Granger, é estimar o modelo sem preocupar-se, inicialmente, com os resultados e com o possível problema de correlação espúria, uma vez que se analisarmos os resíduos provindos destas regressões e estes tiverem um comportamento que seja procedente com o de séries de tempo que são integráveis de ordem inferior à ordem de suas variáveis em nível, pode-se afirmar que os resultados dos testes t e F são válidos, de forma a poderem ser utilizados, uma vez que as duas variáveis em nível têm um equilíbrio no longo prazo.

Prosseguimos com a estimação da equação, de onde obtemos os seguintes resultados das regressões para os diversos países, sempre baseados no modelo observado em (4), conforme Tabela 2. 


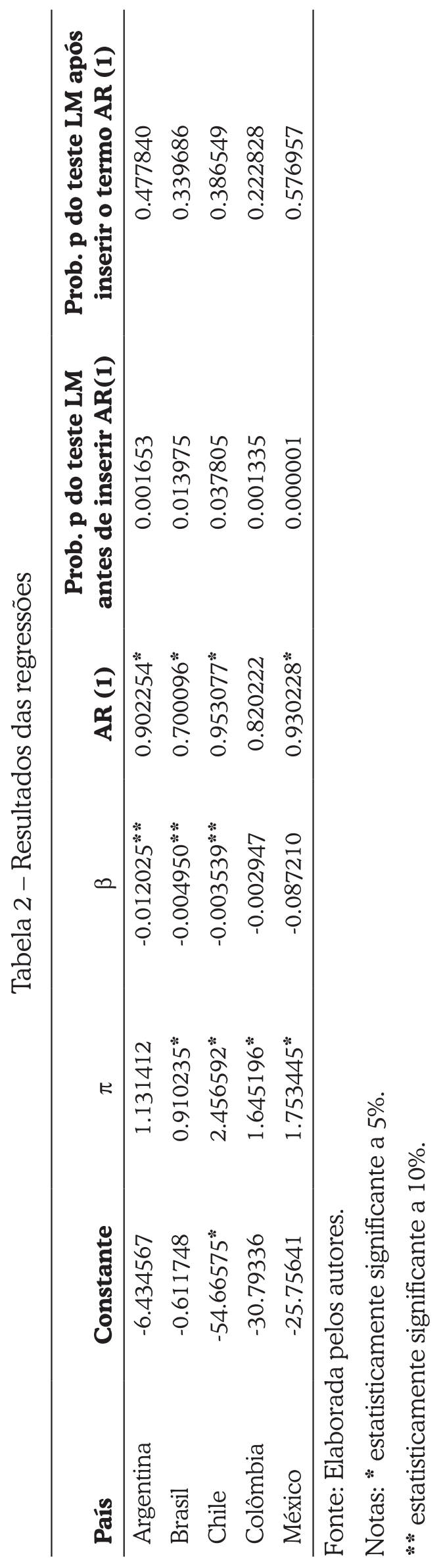

ESTEVES, L. E.; CORREIA, F. M. Crescimento econômico e Lei de Thirlwall: uma análise... 
A Tabela 2 sumariza os resultados obtidos com as cinco regressões realizadas para os países da amostra. As regressões demonstraram que a maioria dos parâmetros constantes das regressões baseadas na equação (4) não são estatisticamente significativas ao nível de significância de $10 \%$, sendo que o único país que apresentou uma constante significativa com probabilidade $\mathrm{p}$ sendo de 0,0036 , foi o Chile.

Um parâmetro relacionado à elasticidade renda das importações chama a atenção já que tem um valor relativamente baixo com relação aos demais, sendo este o parâmetro da elasticidade para o caso brasileiro. Este caso pode ser explicado pelas restrições severas impostas ao país durante a década de 1980, e depois, pela euforia da década de 1990. Durante a década de 1980, houve um comprometimento de recursos para o pagamento das dívidas, o que gerou uma redução das importações, em conjunto com uma queda do produto observado pelo país nos primeiros anos desta década. Mas após um breve período de recessão, houve um vigoroso aumento do produto em conjunto com uma restrição externa que impunha ao país uma redução na quantidade de bens a serem importados. Já na década de 1990, houve uma elevação surpreendente das importações devido às políticas aplicadas naquele período que visavam à contenção da inflação, o que gerou um crescimento das importações mais que proporcionais ao crescimento do produto do país. Este comportamento, aliado às expectativas dos agentes do mercado, sofrendo de sucessivos períodos de bonança de divisas externas e de restrições na liquidez do mercado internacional que eram observadas nos fluxos da conta capital, acabaram por influenciar a elasticidade renda das importações.

Podemos comparar as elasticidades obtidas neste trabalho com as elasticidades de longo prazo obtidas no trabalho de Lopez e Cruz (2000), onde estes autores estimam elasticidades renda das importações para quatro países, obtendo os seguintes valores: Argentina: 2,8; Brasil: 1,03; Colômbia: 1,8; México: 1,3.

A comparação não traz uma boa informação ao leitor, mas serve como uma prova de robustez para os resultados apresentados. Esta comparação deve ser realizada sabendo-se que o trabalho realizado por Lopez e Cruz (2000) leva em consideração um período de tempo diferente do escolhido para este trabalho. Contudo, não podemos deixar de ressaltar a semelhança entre os dados obtidos com relação às elasticidades entre o trabalho de Lopez e Cruz (2000) e o presente estudo.

Ainda observando a Tabela 2, encontramos uma relação importante se estivermos dispostos a aceitar um nível de significância de $10 \%$. Vê-se que os coeficientes das variáveis dummies interativas com a renda são todos significativos para Argentina, Brasil e Chile, além de apresentarem o sinal esperado. Assim, pode-se inferir que em períodos em que haja uma fuga de capitais, tal que a conta corrente opere com o sinal negativo, a elasticidade renda da demanda por importações será reduzida momentaneamente. Este fato pode ser explicado pelas expectativas 
dos agentes em relação à quantidade de divisas externas disponíveis para o país naquele momento. Contudo, não está claro se este fato também pode ser causado por uma antecipação de expectativas com relação ao crescimento futuro da economia, que seria sentido primeiramente pelo fluxo de capitais, devido ao seu dinamismo, e logo após, sentido pela contração tanto do produto e consequentemente da renda do país. Aqui, deixamos em aberto a explicação para este fato, simplesmente chamando a atenção dos leitores para o fato de que existe uma relação entre a conta corrente e a elasticidade renda das importações, sendo esta positiva, o que demonstra que, inicialmente, um fluxo de capitais negativo está ligado a uma contração na elasticidade renda das importações.

Para que os resultados das regressões e as discussões sobre os parâmetros façam sentido, é necessário, pela metodologia Engle-Granger, que os resíduos sejam estacionários, ou seja, que sejam integrados de ordem zero. É interessante ressaltar o caso do Chile, onde pela Tabela 1, vimos que os resíduos eram estacionários, não incorrendo em nenhum problema com relação à regressão espúria. Mesmo assim, testam-se os resíduos para observar se estes também geraram séries estacionárias. Os resultados dos testes, levando em consideração o critério de Schwarz para a escolha da melhor representação, com tendência, intercepto e o número de defasagens. Os resultados são demonstrados na Tabela 3. 


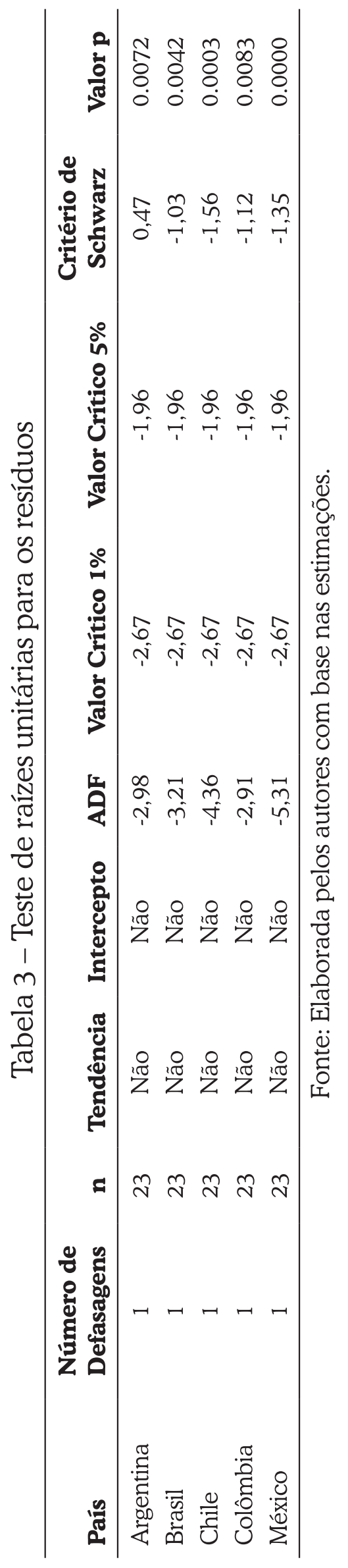


Observa-se, sem nenhuma distinção entre países, que todos os resíduos comportam-se como séries estacionárias, tanto ao nível de significância de $5 \%$, quanto ao nível de $1 \%$. Portanto, demonstrando robustez nos resultados obtidos.

A última discussão persiste sobre o fato da intensidade dos valores dos parâmetros correspondentes às variáveis dummies, i.e., por que a intensidade deste é maior para a Argentina e para o México, do que para os demais países latino-americanos?

A alternativa obtida na tentativa de mensurar esta distância que ocorre entre os países, é observar o quanto a conta capital é essencial para se obter divisas estrangeiras para o país. Para tal mensuração, supõe-se que os países só têm duas fontes de recursos estrangeiros: a primeira é via exportações, que gera entrada de divisas como um resultado da venda das mercadorias; e a segunda corresponde à entrada de recursos via conta capital. Assim, formula-se a Tabela 4, a qual demonstra a razão entre as exportações e a conta capital, como uma média do período 1980-2005. Uma vez que o objetivo desta média é simplesmente observar a importância da conta capital para a obtenção de divisas externas do país, ou seja, a importância relativa da conta capital frente as exportações de bens e serviços. Assim, quando a conta capital apresenta valores negativos, estes foram tomados em módulo, de maneira a observar somente o efeito que estes recursos representam com relação às exportações. Esta medida visa demonstrar a real importância da conta capital frente às exportações, de forma a gerar um índice de importância relativa, de modo a que, quanto menor for o valor obtido desta relação, maior é a importância da conta capital para o saldo no Balanço de Pagamento, e sucessivamente, maior é a importância da conta capital para a determinação do crescimento restrito pela balança de pagamentos.

Tabela 4 - Comparação entre os coeficientes obtidos da variável dummy

\begin{tabular}{lccc}
\hline Países & $\begin{array}{c}\text { Média da razão exportações-saldo na } \\
\text { conta capital - 1980-2005 }\end{array}$ & $\begin{array}{c}\text { Coeficiente da } \\
\text { Dummy }\end{array}$ & Prob. p \\
\hline Argentina & 0,0000024080 & -0.012025 & 0.0223 \\
Brasil & 18943,92573 & -0.004950 & 0.0999 \\
Chile & 360650757043,27 & -0.003539 & 0.0816 \\
Colômbia & 2447259519 & -0.002947 & 0.1471 \\
México & 2,942638988 & -0.087210 & 0.1867 \\
\hline
\end{tabular}

Fonte: Elaborada pelos autores com base nas estimações.

Como podemos observar, quanto menor a razão média entre exportaçõessaldo da conta capital, mais importante é a conta capital para o país em questão. Portanto, observando a Tabela 4, temos que a Argentina, durante o período 19802005 , foi o país que mais dependeu dos recursos provenientes da sua conta capi- 
tal para a aquisição de divisas, isto porque a conta capital teve uma importância singular na geração, ou absorção das divisas externas, uma vez que foi o único país a observar um coeficiente menor que 1. Enquanto que o Chile foi o país que teve a maior relação média entre as exportações e a conta capital, i.e., é o país da nossa amostra que demonstrou ter uma conta capital baixa, em relação ao nível de exportações que o país obteve.

Realizando comparações dois a dois, observamos que países com uma maior razão entre exportações-conta capital, acabavam por observar uma menor sensibilidade no parâmetro estimado da dummy. Estas comparações só não procedem quando observamos a comparação entre Colômbia e Chile, e entre Argentina e México. Isto porque a Colômbia, mesmo tendo uma menor razão entre exportações-conta capital, acaba por ter um menor coeficiente da dummy, em relação ao Chile, enquanto a Argentina têm uma razão muito menor que a México, mas um coeficiente da dummy, também menor.

Entretanto, retirando-se estes dois casos, parece ser possível generalizar para o caso destes países latino-americanos que o parâmetro da variável dummy tem se mostrado mais sensível aos choques provenientes das restrições externas nos países onde a conta capital, com relação às exportações, tem uma maior importância.

\section{Considerações Finais}

Para os países latino-americanos aqui estudados, a lei de Thirlwall parece ser uma boa representação para a trajetória de crescimento destes, sendo esta determinada fundamentalmente, pelas exportações e pela elasticidade renda das importações. O presente trabalho demonstra a importância dos fluxos de capitais, não para colocar os países dentro de uma rota de debt-led growth, mas muitas vezes, para suavizar os ajustes requeridos pela lei de Thirlwall, dado um cenário externo desfavorável. Isto porque se a elasticidade renda das importações for constante ao longo dos períodos, dada uma saída de divisas estrangeiras, se o país estivesse em uma trajetória de crescimento baseada no debt-led growth, a queda que deve ocorrer sobre o produto será menor que a determinada pela lei de Thirlwall, pois, quanto mais importante for a conta de capitais para o país, maior será o ajuste na elasticidade renda das importações, de forma a suavizar a tendência a restrições em seu crescimento.

Da mesma forma, o pensamento inverso também pode ser estabelecido, uma vez que uma estratégia de debt-led growth, acabaria por induzir a uma elevação na elasticidade renda da demanda por importações, de forma a reduzir a tendência de crescimento gerada pelo aumento da dívida dos países.

Neste sentido, os resultados indicam que as expectativas dos agentes tendem a influenciar a elasticidade renda das importações de maneira a suavizar as restri- 
ções impostas pela lei de Thirwall aos países latino-americanos selecionados. Além destas evidências, ao comparar-se a importância relativa da conta corrente sobre o Balanço de Pagamentos, verificou-se que existe certa relação entre a intensidade do coeficiente da variável dummy com a importância relativa da conta corrente. Assim de maneira geral, pode-se afirmar que quanto maior for a importância relativa da conta corrente em relação às exportações, maior deve ser a intensidade de variação sobre a elasticidade renda das importações, de maneira a suavizar a restrição que é imposta ao crescimento pela lei de Thirlwall no curto prazo.

Acredita-se que este fato esteja diretamente correlacionado com as expectativas dos agentes ao conhecerem a importância da conta capital para a obtenção de divisas externas, bem como anteciparem, de certa maneira, alguma medida governamental, ou mesmo uma tendência de desestímulo às importações.

\section{Referências}

ADELMAN, I. Teorias do desenvolvimento econômico. Rio de Janeiro: Forense, 1972.

BARANZINI, M. A theory of wealth distribution and accumulation. Oxford: Clarendon Press, 1991.

BARBOSA-FILHO, N. H. Growth, exchange rates and trade in Brazil: a structuralist postKeynesian approach. Nova Economia, Belo Horizonte, v. 14, n. 2, p. 59-86, maio 2004.

BÉRTOLA, L.; HIGACHI, H.; PORCILE, G. Balance-of-paymentsconstrained growth in Brazil: a test of Thirlwall's Law, 1890-1973, Journal of Post Keynesian Economics, Armonk, v. 25, n. 1, Dec./Mar. 2002.

DOMAR, E. Capital expansion, rate of growth, and employment. Econometrica, Chicago, v. 14, n. 2, p. 137-147, Apr. 1946.

HARROD, R. F. Essay in dynamic theory. The Economic Journal, Cambridge, v. 49, p.14-33, Mar. 1939.

JONES, H. G. Modernas teorias do crescimento econômico. São Paulo: Atlas, 1979.

KALDOR, N. Alternative theories of distribution. Review of Economic Studies, Bristol, v. 23, n. 2, p. 83-100, 1956.

LÓPEZ, J.; CRUZ, A. Thirlwall's law and beyond: the Latin American experience. Journal of Post Keynesian Economics, Armonk, v. 22, n. 3, p. 477-495, Mar./June 2000.

LUCAS, R.E. Jr. On the mecanics of economic development. Journal of Monetary Economics, Amsterdam, v. 22, n.1, p. 3-42, 1988.

McCOMBIE, J. 'Thirlwall`s Law' and balance of payments coinstrained growth: a comment on the debate. Applied Economics, London, v. 21, n. 5, p. 611-629, 1989.

McCOMBIE, J. On the empirics of balance-of-payments-constrained growth. Journal of Post Keynesian Economics, Armonk, v. 19, n. 3, Mar. /June 1997.

McCOMBIE, J.; THIRLWALL, A. Economic growth and the balance of payments constraint, New York: St. Martin`s Press, 1994. 
MORENO-BRID, J. C.; PÉREZ, E. On capital flows and the balance-of-payments constrained growth model. Journal of Post Keynesian Economics, Armonk, v. 21, n. 1, p. 115-137, Sept. / Dec. 1999.

PASINETTI, L. L. Rate of Profit and Income Distribution in Relation to the Rate of Economic Growth. Review of Economic Studies, Bristol, v. 29, p. 262-279, Oct. 1962.

Growth and income distribution: essays in economic theory. Cambridge: Cambridge University Press, 1979.

PREBISCH, R. The economic development of Latin America and its principal problems. New York: ECLA, 1950.

ROMER, P. M. Increasing returns and long run growth. Journal of Political Economy, Chicago, v. 94, n. 5, p. 1002-1037, Oct. 1986.

SOLOW, R. A contribution to the theory of economic growth. Quarterly Journal of Economics, Cambridge, v. 70, n. 1, p. 65-94, Feb. 1957.

TAVARES, M.C. Da substituição de importações ao capitalismo financeiro. Rio de Janeiro: Zahar, 1972.

THIRLWALL, A. The balance of payments constraint as an explanation of international growth rates differences. Banca Nazionale del LavoroQuarterly Review, Roma, v. 128, p. 45-53, 1979.

THIRLWALL, A. P.; HUSSAIN, M. N. The balance of payments costraint, capital flows and growth rate differences between developing countries. Oxford Economic Papers, v. 34, n. 3, p. 498-509, Nov. 1982.

Recebido em: 16/09/2010.

Aceito em: 23/12/2010. 